notified between 1960 and 1966, 10 were associated with bonemeal contact, and five of these were in agricultural or horticultural workers. Thus, in view of the many hundreds of tons of potentially dangerous material imported each year, and its wide distribution to the general population, the infectivity must indeed be very low.

We are grateful to Dr. T. Parkinson and Dr. W. Stokes for allowing these cases to be published, and to Dr. R. M. Dykes and
Dr. J. J. A. Reid, medical officers of health. We are indebted to Mr. J. Harrison for preparing the photographs.

Requests for reprints should be addressed to Dr. A. H. Knight, Renal Unit, Royal Free Hospital, North-west Branch, Lawn Road, London N.W.3.

\section{REFERENCE}

Ministry of Labour (1959). Report of the Committee of Inquiry on Anthrax, Cmnd. No. 846, p. 47. H.M.S.O., London.

\title{
Timing of Atropine and Neostigmine in the Reversal of Muscle Relaxants
}

\author{
J. G. HANNINGTON-KIFF,* M.B., B.SC., F.F.A. R.C.S.
}

\begin{abstract}
Summary : The antimuscarinic effects of atropine were $\checkmark$ studied in 46 patients to whom neostigmine had been given after operation to reverse the action of a muscle relaxant. Neostigmine was given to alternate patients three minutes after, or together with, atropine, and the effects of the two procedures were compared by measuring the secretions which collected in the buccal and oropharyngeal cavities and observing the heart rate.

It was found that the glands of the oral cavity were stimulated to a greater extent when neostigmine was given with atropine than after atropine. Any dose of atropine sufficient to inhibit peristaltic movements of the bowel is more than enough to block completely secretion by the salivary glands, and the appearance of some secretion in all cases after the administration of neostigmine suggests that the bowel was at liberty to react to the neostigmine in every case, but perhaps particularly so when atropine and neostigmine were given mixed. The integrity of an anastomosis of the bowel could be endangered by vigorous peristalsis in the early postoperative period.

Electrocardiograms in about half the patients from each group confirmed earlier work that the muscarinic effects of neostigmine on the heart can be prevented by giving the atropine either before or together with the neostigmine.
\end{abstract}

\section{Introduction}

Neostigmine methylsulphate is routinely used to reverse the action of non-depolarizing muscle relaxants postoperatively, and its muscarinic effects are minimized by the administration of atropine. It is known that in certain circumstances atropine can give rise to an initial bradycardia (Innes and Nickerson, 1965) and, to avoid the possibility of a summation of the slowing effects of atropine and neostigmine on the heart, it is usual to administer atropine and wait some minutes for a tachycardia to be established before giving neostigmine. However, the need for preceding neostigmine by atropine has been questioned, since it has been shown that the initial effect of atropine and neostigmine mixture is tachycardia (Kemp and Morton, 1962 ; Baraka, 1968).

* Lecturer in Anaesthetics, University of Bristol.
It must be appreciated that it remains to be shown whether the muscarinic effects of neostigmine are as effectively blocked in organs other than the heart when given mixed with atropine rather than after atropine in the classical manner. The results are reported here of an initial study to compare the amount of secretion from the glands of the oral cavity when neostigmine is given together with and after atropine.

\section{Patients and Methods}

In a consecutive series of cases for laparotomy anaesthetized by me, tubocurarine was reversed in alternate patients with neostigmine preceded by or simultaneously with atropine. The patients may thus be divided into two groups according to the timing of the atropine and neostigmine. There was no significant difference with regard to age and sex between the two groups (see Table) and the types of abdominal operations included in each group were comparable. Forty-eight patients were investigated, but the results in two of these have been omitted, as the course of their anaesthesia was uneven.

\begin{tabular}{|c|c|c|c|c|}
\hline \multicolumn{2}{|l|}{ 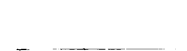 } & \multicolumn{2}{|c|}{ Details of Patients in the Study } & \multirow[b]{2}{*}{$\begin{array}{l}\text { Atropine with } \\
\text { Neostigmine }\end{array}$} \\
\hline $\begin{array}{r}\text { Age } \\
\text { in }\end{array}$ & roups & & $\begin{array}{l}\text { Atropine before } \\
\text { Neostigmine }\end{array}$ & \\
\hline \multicolumn{3}{|c|}{$\begin{array}{l}20-29 \\
30-39 \\
40-49 \\
50-59 \\
60-69\end{array}$} & $\begin{array}{l}4 \text { patients } \\
3 \text { patients } \\
8 \text { patients } \\
6 \text { patients } \\
2 \text { patients }\end{array}$ & $\begin{array}{l}5 \text { patients } \\
5 \text { patients } \\
6 \text { patients } \\
4 \text { patients } \\
3 \text { patients }\end{array}$ \\
\hline $\begin{array}{l}\text { Males } \\
\text { Females }\end{array}$ & $\begin{array}{l}. \\
\cdots\end{array}$ & . & $\begin{array}{l}10 \text { patients } \\
13 \text { patients }\end{array}$ & $\begin{array}{l}11 \text { patients } \\
12 \text { patients }\end{array}$ \\
\hline & Total & $\ldots$ & 23 patients & 23 patients \\
\hline
\end{tabular}

\section{Details of Anaesthesia}

Premedication was with pethidine $1 \mathrm{mg} . / \mathrm{kg}$. and atropine $0.01 \mathrm{mg} . / \mathrm{kg}$. one hour before operation. General anaesthesia was induced with intravenous thiopentone $3-4 \mathrm{mg}$. $/ \mathrm{kg}$. and a cuffed endotracheal tube was passed after intravenous suxamethonium $0.8 \mathrm{mg} . / \mathrm{kg}$. Anaesthesia was maintained with nitrous oxide and oxygen with mechanical ventilation, and muscle relaxation was continued with intravenous tubocurarine $5-7 \mathrm{mg}$. $/ \mathrm{kg}$., which was reversed with neostigmine $0.04 \mathrm{mg}$./ $\mathrm{kg}$. and atropine $0.02 \mathrm{mg}$. $/ \mathrm{kg}$. The atropine was given either three minutes before or together with the neostigmine in alternate cases. 


\section{February 1969}

\section{Collection of Secretions}

Secretions were collected from the buccal and oropharyngeal cavities by swabbing with weighed pieces of gauze which were then reweighed and the difference was calculated to the nearest $0.5 \mathrm{~g}$. In the event of copious secretion its collection was facilitated by aspirating the bulk into a syringe through a length of flexible tube and expelling the contents on to a swab for weighing ; the remaining secretion was then collected as usual by swabbing. Secretions were collected every 15 minutes during the course of the anaesthetic.

At the time of reversal of tubocurarine the management of the patients became different. In those patients who received atropine before neostigmine the atropine was given at the end of the last 15-minute period and three minutes later neostigmine was given. In no case did a measurable quantity of secretion collect in the oropharynx during this three-minute interval. Secretions were then collected in the five minutes after the neostigmine. In the other patients the secretions were collected in the five minutes after the atropine and neostigmine mixture. All injections were made into rapidly running intravenous infusions and were made in less than five seconds. The flow of anaesthetic gases and intermittent positive-pressure ventilation were continued during the five-minute period, when secretions were collected in all cases. It was most important to maintain even anaesthesia, as any swallowing movements made by the patient caused the appearance of extra secretion in the presence of the endotracheal tube and two patients had to be omitted from the series on this account.

\section{Results}

The secretion collected in the first 15-minute period was higher than that in subsequent 15 -minute periods, as it included secretion present in the patient's oropharynx at induction. Once a steady state was reached the secretions in consecutive 15-minute periods were quite constant for each patient, and

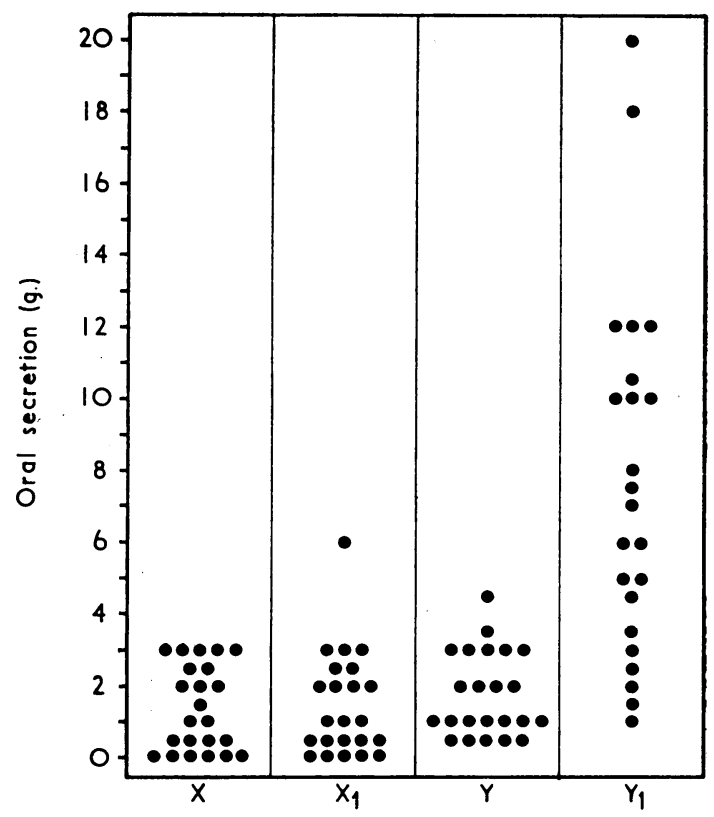

FIG. 1.-Distribution of the weights of oral secretions before and after reversal of muscle relaxant with neostigmine. $\mathrm{X}=$ Control secretions in 15 minutes before the administration of atropine followed by neostigmine. $\mathrm{X}_{1}=$ Control secretions in 15 minutes before the adminstration of atropine mixed with neostigmine. $\mathrm{Y}=$ Secretions in five minutes after neostigmine preceded by atropine. $Y_{1}=$ Secretions in five minutes after neostigmine mixed with atropine. Analysis of groups by the Wilcoxon-White ranks test: $X$ and $X_{1}$ sum of ranks 538:575, not significant; $Y$ and $Y_{1}$, sum of ranks $324: 757, P<0.01$ for the purposes of this study the quantity of secretion collected in the last 15-minute period in each case was used as control and compared with the amount of secretion obtained in the five-minute interval after neostigmine, either preceded by atropine or with atropine. The weights of secretions in the control groups ( $\mathrm{X}$ and $\mathrm{X}_{1}, \mathrm{Fig} .1$ ) and those in the postneostigmine groups ( $\mathrm{Y}$ and $\mathrm{Y}_{1}$, Fig. 1) are not normally distributed ; these results were therefore analysed by the WilcoxonWhite ranks test, which is distribution-free (non-parametric). There is no significant difference between the weights of secretions in the control groups, but following reversal of muscle relaxant more secretion was found on the whole after the neostigmine and atropine mixture than after neostigmine preceded by atropine, and this difference is significant at the $1 \%$ level.

The control and post-neostigmine secretions do not appear to be related to the age, sex, or weight of the patients. There is, however, a positive correlation between the control secretions and those after neostigmine, and regression lines have been calculated for each group of patients, disregarding the absence of a normal distribution of results; it can be seen from Fig. 2 that a linear description of the association is reasonable.

In just over half the cases in each group an electrocardiograph was continuously recording on paper during the reversal period, and analysis of the records showed that in all cases where atropine and neostigmine mixture was given the initial effect was tachycardia, substantially as described by Kemp and Morton (1962). It would appear, therefore, that the muscarinic effects of neostigmine on the heart can be prevented by giving the atropine either before or mixed with the neostigmine. The pulse rates later in the ward showed no obvious difference between patients who had been given neostigmine together with or preceded by atropine.

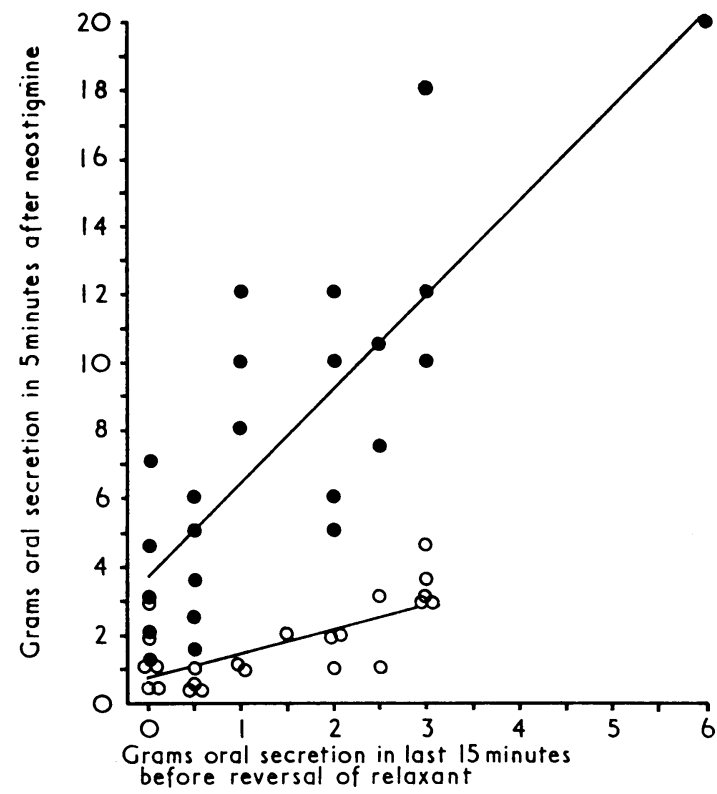

FIG. 2.- Scatter diagram which illustrates the positive correlation between the amounts of oral secretion before and after reversal of muscle relaxant with neostigmine. Open circles $=$ Neostigmine preceded by atropine ; regression of $\mathrm{Y}$ on $\mathrm{X}, \mathrm{Y}=0.69 \mathrm{X}+0.82$ Closed circles Neostigmine $\mathrm{X}_{1}, \mathrm{Y}_{1}=2 \cdot 82 \mathrm{X}_{1}+3 \cdot 59$.

\section{Discussion}

The results show that a dose of atropine can more effectively block the muscarinic action of neostigmine on the glands of the oral cavity when it is given some time before the latter drug. If the same applies also to the glands of the bronchial tree, then it would seem wise to precede neostigmine by atropine 
to avoid increased secretion, which could be a serious handicap postoperatively. A study is necessary to establish whether there is an optimum interval by which atropine should precede neostigmine. It is suggested that such a study could well include assessment of the dose ratio of atropine to neostigmine, which appears to have become established largely on the basis of ampoule strength ; for instance, the following average doses are commonly used: atropine $0.6 \mathrm{mg}$. (1 ampoule) to $2.5 \mathrm{mg}$. neostigmine ( 1 ampoule); atropine $1.2 \mathrm{mg}$. ( 2 ampoules) to $2.5 \mathrm{mg}$. neostigmine (1 ampoule); and atropine $1.2 \mathrm{mg}$. ( 2 ampoules) to $5 \mathrm{mg}$. neostigmine ( 2 ampoules).

Any dose of atropine sufficient to inhibit peristaltic movements of the bowel is more than enough completely to have blocked secretion by the salivary glands (Innes and Nickerson, 1965), and the appearance of some secretion in all cases here, after the administration of neostigmine, suggests that the bowel was at liberty to react to the neostigmine in every case, but perhaps particularly so when atropine and neostigmine were given mixed. The integrity of an anastomosis of the bowel could well be endangered by vigorous peristalsis in the early postoperative period, and Bell and Lewis (1968) have drawn attention to the higher incidence of leaks from ileorectal anastomoses in patients who had been given neostigmine than in those who had not ; furthermore, the neostigmine in every case had been given mixed with atropine.

I an grateful to Miss E. H. L. Duncan, senior lecturer in medical statistics, University of Bristol, for the use of a computer programme to calculate the regression lines in Fig. 2.

\section{REFERENCES}

Baraka, A. (1968). Brit. F. Anaesth., 40, 30.

Bell, C. M. A., and Lewis, C. B. (1968). Brit. med. 7., 3, 587

Innes, I. R., and Nickerson, M. (1965). In The Pharmacological Basis of Therapeutics, 3rd ed., edited by L. S. Goodman and A. Gilman, p. 527. New York.

Kemp, S. W., and Morton, H. J. V. (1962). Anaesthesia, 17, 170

\section{Preliminary Communications}

\section{Azathioprine in Rheumatoid Arthritis}

Brit. med. F., 1969, 1, 420-422

Summ mmary : The ability of azathioprine to reduce the corticosteroid requirements of patients with severe rheumatoid arthritis was tested under double-blind conditions against placebo. After 12 months a significant mean dose reduction of $36 \%$ was achieved without undue side-effects. This form of therapy promises to be an advance in the management of severe rheumatoid arthritis.

\section{INTRODUCTION}

Although the aetiology of rheumatoid arthritis remains unknown, there is good evidence that immunological mechanisms play at least a part in the pathogenesis of the disease. Cytotoxic and antimetabolic drugs, which have been shown to suppress not only immune responses in animals and man but also immune-mediated diseases in experimental animals, would therefore seem to offer a logical approach to the treatment of rheumatoid arthritis.

Jiménez Díaz et al. (1951) first reported the effect of nitrogen mustard in this disease, and since then further accounts have appeared describing the use not only of nitrogen mustard Robechi et al. (1954) but also of methotrexate (Enderlin and Gross, 1967 ; Beickert and Geidel, 1968), mercaptopurine (Lorenzen and Videbæk, 1965 ; Myles, 1965 ; Enderlin and Gross, 1967 ; Beickert and Geidel, 1968), chlorambucil (Kahn et al., 1967), cyclophosphamide (Fosdick et al., 1968), and azathioprine (Brocteur and Moens, 1965 ; Lorenzen and Videbæk, 1965 ; Moens and Brocteur, 1965 ; Corley et al., 1966 ; Enderlin and Gross, 1967 ; Lièvre et al., 1967 ; Philips et al., 1967).

All these studies have, however, been without controls, and in a disease such as rheumatoid arthritis, characterized by spontaneous remissions and exacerbations, the accurate and unbiased evaluation of such treatment requires the discipline of doubleblind controlled conditions.
These considerations led us to study the influence on rheumatoid arthritis of azathioprine, a drug extensively tested in organ transplantation. Since azathioprine is a bone marrow suppressant, it was felt justifiable to use the drug only in severe cases ; and in a department where corticosteroid drugs are prescribed only for patients with resistant and progressive disease this seemed the right group to study. Further, as the dose of corticosteroid is always titrated down to the minimum acceptable, the most realistic measure of the effectiveness of azathioprine was felt to be its ability to permit a reduction in this corticosteroid dosage.

We repont here the result of a double-blind controlled trial to determine whether azathioprine, in a dose of $2.5 \mathrm{mg} . / \mathrm{kg}$./ day, could reduce the minimum corticosteroid requirements of outpatients with seropositive, erosive rheumatoid arthritis.

\section{METHODS}

Patients admitted to the trial were required to have definite rheumatoid arthritis with a rheumatoid factor latex test titre greater than $1 / 40$. All had to have received at least $5 \mathrm{mg}$. of prednisolone daily for six months and to have been on a stable dose for at least two months before entering the trial. The minimum haematological criteria were a total white cell count of $4,000 / \mathrm{cu}$. mm, a neutrophil count of $2,500 / \mathrm{cu}$. mm., and a platelet count of $200,000 / \mathrm{cu}$. mm. Premenopausal women were excluded.

Particular care was taken to reduce the steroid dose in each patient to the minimum acceptable before entering the trial. All analgesic drugs except paracetamol, which was used as a supplementary treatment throughout the trial, were withdrawn one month beforehand.

Patients received either azathioprine or matching placebo tablets. Treatments were allocated by a random process by means of a code in which patients were paired and stratified both for sex and initial dose of prednisolone. Each patient attended at intervals of one month, and at each visit the dosage of both prednisolone and paracetamol was modified in the light of an overall clinical assessment made under double-blind conditions. 